1

\title{
Sub-optimal treatment of paediatric migraine in an emergency department: An observational study
}

\section{Sharon Klim BN}

Joseph Epstein Centre for Emergency Medicine Research @ Western Health, Sunshine, Australia and The University of Melbourne, Parkville, Australia.

\section{David Krieser MB BS FRACP (PEM)}

Department of Emergency Medicine, Sunshine Hospital, St Albans, Australia and Department of Paediatrics, Faculty of Medicine, Dentistry \& Health Sciences, The University of Melbourne, Parkville, Australia

\section{Anne-Maree Kelly MD FACEM (Corresponding Author)}

\section{Anne-Maree.Kelly@wh.org.au}

Joseph Epstein Centre for Emergency Medicine Research, Western Health, St Albans, Victoria, Australia and Department of Medicine, Melbourne Medical School - Western Precinct, The University of Melbourne, St. Albans, Victoria, Australia.

\section{Word count:}

Abstract: 99

Main text: 907

References: 7

Tables and figures: 1

Conflicts of interest: None

Funding: Department resources only

This is the author manuscript accepted for publication and has undergone full peer review but has not been through the copyediting, typesetting, pagination and proofreading process, which may lead to differences between this version and the Version of Record. Please cite this article as doi: 10.1111/1742-6723.13355

This article is protected by copyright. All rights reserved. 
Author contrubutions: AMK had the concept for the study, performed the analysis and drafted the manuscript. All authors refined the data collection tool and refined the manuscript. SK collected the data.

This article is protected by copyright. All rights reserved. 


\section{ABSTRACT}

Objective: To describe treatment of children presenting to an Australian Emergency Department (ED) with a final ED diagnosis of migraine.

Methods: Planned substudy of a retrospective cohort study of the epidemiology of headache in children. Primary outcome of interest was treatment administered in the ED.

Results: Thirty-five children were studied. The most commonly used medications were nonsteroidal anti-inflammatory drugs, paracetamol and ondansetron. Specific antimigraine therapy was used uncommonly. Fourteen percent of children received an opiate.

Conclusion: Treatment of migraine in children was not consistent with the available evidence regarding agents' relative effectiveness. The use of opiates is concerningly high. 


\section{INTRODUCTION}

Headache is the chief complaint for about $1 \%$ of paediatric emergency department (ED) attendances of whom $8.5 \%-18.5 \%$ are due to migraine.[1,2] A recent systematic review has found limited evidence comparing the effectiveness of therapies.[3] Included studies were largely confined to placebo-controlled rather than comparative trials. It found that ibuprofen (RR 1.87) and triptans (children: RR 1.67; adolescents: RR 1.32) were superior to placebo. Neither paracetamol nor dihydroergotamine was superior to placebo. Dopamine receptor antagonists are little studied in children. One small study compared intravenous prochlorperazine and ketorolac and reported that significantly more children had a pain score reduction of $>50 \%$ at one hour with prochlorperazine. [4]

Little is known about treatment of paediatric migraine in ED and its concordance with the available evidence-base. Canadian data shows considerable variation in practice.[5] Australasian data reported that the most commonly used agents were non-steroidal antiinflammaory agents (NSAID, 30\%) followed by paracetamol (24\%).[6] The use of defined antimigraine medications (chlorpromazone, sumitritan, prochlorperazine) was low (8\%). Eleven percent of children received morphine and a further $25 \%$ a codeine-containing medication.

The aim of this study was to describe the treatment provided to children presenting to an Australian ED with an final ED diagnosis of migraine.

\section{METHODS}

This was a planned substudy of a retrospective cohort study by medical record review of the epidemiology of headache in children presenting to ED. It was conducted at Sunshine 
Hospital, a university-affiliated community hospital with an annual paediatric census of approximately 25,000 .

Incluison criteria were presentation between 1 January and 31 December 2016 with headache as a major symptom and age 2-16 years. Exclusion criteria were a history of head trauma within the previous 48 hours, a ventriculoperitoneal shunt in situ or known intracranial conditions associated with headache. This substudy includes the cohort with an ED discharge diagnosis of migraine as recorded in the treating doctor's clinical notes as free text. The primary outcome of interest for this substudy was the treatment administered in the ED. Data was analysed by descriptive statistics using Analyse-It (Leeds, UK). The project was approved by the Western Health Low Risk Ethics Panel. Patient consent for data collection was not required.

\section{RESULTS}

Thirty-five children had a discharge diagnosis of migraine (15.5\% of total cohort). Median age was 11 (IQR 8-15); 51\% were male. Pain score data is available for 20 children. Median initial pain score was 5 (IQR 2-7). Median pre-discharge pain score was 0.5 (IQR 0-5). Nine children had a reduction in pain score of $\geq 2$ points $(45 \%, 95 \% \mathrm{Cl} 25.9-65.8 \%)$. Seven children had a pain score $\geq 4$ at ED discharge (35\%, 95\% Cl 8.1-56.7\%).

Medications given are shown in table 1 . Note, more than one medication could be prescribed. Fourteen percent of children received an opiate (95\% Cl 6.3-29.4\%). Regarding paracetamol, in 4 cases it was nurse-initiated before medical assessment. In three of these additional medications were prescribed by the assessing doctor.

This article is protected by copyright. All rights reserved. 
Three children were admitted to hospital for further investigation and treatment $(8.6 \%, 95 \%$ Cl 3-22.4\%).

\section{DISCUSSION}

The available evidence regarding the relative effectiveness of migraine treatments for children is limited, however, what there is suggests that some treatments are more effective than others. It is also probably reasonable to extrapolate from adult data that opiates are relatively ineffective.

Our data suggests that treatment of paediatric migraine is sub-optimal. There is high usage of paracetamol which has been shown to be ineffective in a recent Cochrane review.[3] The high use of paracetamol may be due to it being recommended in local clinical guidelines for the treatment of headache, despite the research findings.[7] Closer review of these guidelines makes age-based recommendations for ibuprofen, chlorpromazine, aspirin ro sumitriptan when migraine is the most likely diagnosis.

There is low usage of proven antimigraine treatments (phenothiaizines, triptans and metoclopramide, $9 \%$ combined). While the use of codeine-containing medications has reduced compared to the PREDICT study,[6], the proportion of patients receiving an opiate is concerningly high (14\%). There would appear to have been little improvement in the use of evidence-based therapies since the PREDICT audit [6]. The reduction in the use of codeine-containing medications between the PREDICT study and this study may be due to efforts, including by givernment, to reduce use of these medications.

Reasons for poor compliance with the evidence may include lack of knowledge about recommended migraine treatment for children and concern about adverse effects (including 
extrapyramidal effects and sedation) with some medications. There may also have been a preference to avoid parenteral medications, especially in younger children.

In order to improve prescribing of effective antimigraine therapy in children, two main interventions are needed: high-quality comparative research and development and dissemination of evidence-based guidelines specific to migraine treatment for children and adolescents.

This study has some limitations. It is single centre and thus may not be generalizable, although the findings were very similar to those of the PREDICT audit which was multicentre.[6] Migraine was the clinical diagnosis made by the treating clinician so it is possible some cases were miscoded. This is the 'real world' situation in ED. Data was collected from medical records so may be subject to missing data. The study sample was relatively small, resulting in wide confidence intervals around the point estimate

\section{CONCLUSION}

Treatment of migraine in children was not consistent with the available evidence regarding agents' relative effectiveness. The rate of use of opiates is concerningly high. More work is needed to increase the evidence-base, develop pathways and educate clinicians about effective therapeutic approaches to paediatric migraine.

This article is protected by copyright. All rights reserved. 
Table 1. Treatments administered

\begin{tabular}{|l|c|}
\hline Medication & $\mathbf{N}, \%, 95 \% \mathbf{C l}$ \\
\hline Nonsteroidal anti-inflamatory & $23,66 \%, 49-79 \%$ \\
\hline Paracetamol & $18,51 \%, 36-67 \%$ \\
\hline Ondansetron & $14,40 \%, 26-56 \%$ \\
\hline Oxycodone & $4,11 \%, 5-26 \%$ \\
\hline Phenothiazine & $3,9 \%, 3-22 \%$ \\
\hline Triptan & $1,3 \%, 0.5-15 \%$ \\
\hline Metoclopramide & $1,3 \%, 0.5-15 \%$ \\
\hline Paracetamol/ codeine & $1,3 \%, 0.5-15 \%$ \\
\hline Intranasal fentanyl & $1,3 \%, 0.5-15 \%$ \\
\hline None & $5,14 \%, 6-29 \%$ \\
\hline
\end{tabular}

\section{REFERENCES}

1. Conicella E, Raucci U, Vanacore N, Vigevano F, Reale A, Pirozzi N et al. The Child With Headache in a Pediatric Emergency Department. Headache 2008;48:1005-1011.

2. Kan L, Nagelberg J, Maytal J. Headaches in a Pediatric Emergency Department:

Etiology, Imaging, and Treatment. Headache 2000;40:25-29.

3. Richer L, Billinghurst L, Linsdell MA, Russell K, Crumley ET, Durec T et al. Drugs for the acute treatment of migraine in children and adolescents. Cochrane Database Syst Rev 2016; Apr 19: 4:CD005220.

This article is protected by copyright. All rights reserved. 
4. Brousseau DC, Duffy SJ, Anderson AC, Linakis JG. Treatment of pediatric migraine headaches: a randomized, double-blind trial of prochlorperazine versus ketorolac. Ann Emerg Med. 2004 Feb;43(2):256-62.

5. Richer LP, Laycock K, Millar K, Fitzpatrick E, Khangura S, Bhatt M et la. Treatment of children with migraine in emergency departments: national practice variation study.

Pediatrics 2010; 126:e150-5.

6. Herd DW, Babl FE, Gilhotra Y, Huckson S, PREDICT group. Pain management practices in paediatric emergency departments in Australia and New Zealand: a clinical and organizational audit by National Health and Medical Research Council's National Institute of Clinical Studies and Paediatric Research in Emergency Departments International Collaborative. Emerg Med Australas 2009; 21:210-21.

7. Royal Children's Hospital. Clinical Practice Guideline: Headache. https://www.rch.org.au/clinicalguide/guideline_index/Headache/ Accessed 21 May 2019. 


\section{University Library}

\section{- M M N E R VA A gateway to Melbourne's research publications}

Minerva Access is the Institutional Repository of The University of Melbourne

Author/s:

Klim, S;Krieser, D;Kelly, A-M

Title:

Sub-optimal treatment of paediatric migraine in an emergency department: An observational study

Date:

2019-07-25

Citation:

Klim, S., Krieser, D. \& Kelly, A. -M. (2019). Sub-optimal treatment of paediatric migraine in an emergency department: An observational study. EMERGENCY MEDICINE AUSTRALASIA, 31 (5), pp.879-881. https://doi.org/10.1111/1742-6723.13355.

Persistent Link:

http://hdl.handle.net/11343/286205 